\title{
Risk assessment and shared care planning in out-patient forensic psychiatry: cluster randomised controlled trial
}

\author{
N. A. C. Troquete, R. H. S. van den Brink, H. Beintema, T. Mulder, T. W. D. P. van Os, \\ R. A. Schoevers and D. Wiersma
}

\section{Background}

Forensic psychiatry aims to reduce recidivism and makes use of risk assessment tools to achieve this goal. Various studies have reported on the predictive qualities of these instruments, but it remains unclear whether their use is associated with actual prevention of recidivism in clinical care.

\begin{abstract}
Aims
To test whether an intervention combining risk assessment and shared care planning is associated with a reduction in violent and criminal behaviour

\section{Method}

A cluster randomised controlled trial (Netherlands Trial Register number NTR1042) was conducted in three outpatient forensic psychiatric clinics. The intervention comprised risk assessment with the Short Term Assessment of Risk and Treatability (START) and a shared care planning protocol formulated according to shared decision-making principles. The control group received usual care. The
\end{abstract}

outcome consisted of the proportion of clients with violent or criminal incidents at follow-up.

\section{Results}

In total 58 case managers and 632 of their clients were included. In the intervention group $(n=310), 65 \%$ received the intervention at least once. Findings showed a general treatment effect (22\% of clients with an incident at baseline v. $15 \%$ at follow-up, $P<0.01$ ) but no significant difference between the two treatment conditions (odds ratio $(\mathrm{OR})=1.46$, $95 \% \mathrm{Cl} 0.89-2.44, P=0.15$ )

\section{Conclusions}

Although risk assessment is common practice in forensic psychiatry, our results indicate that the primary goal of preventing recidivism was not reached through risk assessment embedded in shared decision-making.

\section{Declaration of interest}

None.
The main objective of forensic psychiatric treatment is to prevent future violent behaviour. According to the Risk-Need-Responsivity model, ${ }^{1}$ this is best achieved by systematic assessment of the patient's risks for violence and by focusing treatment on these criminogenic needs. The Good Lives model extends this idea by emphasising the importance of strengthening protective factors to help clients build a 'good life' they are reluctant to lose. ${ }^{2}$ Various risk assessment instruments have been developed, recently also including assessment of protective factors, such as the Short Term Assessment of Risk and Treatability (START) ${ }^{3,4}$ and the Structured Assessment of PROtective Factors (SAPROF). ${ }^{5}$ Research on these instruments, however, has focused almost exclusively on their predictive capabilities. Whether the use of risk assessment instruments in forensic psychiatry actually helps to prevent violent behaviour, through the selection of more suitable or better treatment, remains unclear. ${ }^{6}$ Our study addressed this question in out-patient forensic psychiatry, a setting that calls for an ongoing process of assessment and management of short-term variable risks and needs, ${ }^{7-10}$ and specific attention to client motivation for treatment, which is often enforced but no longer mandatory (see online data supplement). ${ }^{7}$ Shared decision-making has been shown to increase client satisfaction, treatment adherence and quality of life in longer-lasting treatment relations, ${ }^{11}$ and thus, in line with the Good Lives model, is thought to be associated with reduced recidivism. ${ }^{2}$ We therefore developed a method of periodically monitoring violence risks and treatment needs, ${ }^{10}$ aimed to foster shared decision-making by actively involving the person receiving forensic out-patient psychiatric care in risk assessment and care planning. This method's ability to prevent violent behaviour in these individuals is tested here.

\section{Method}

The Risk Assessment and Care Evaluation (RACE) study is a cluster randomised controlled trial (RCT), registered with The Netherlands Trial Register (NTR1042), which was conducted in The Netherlands between September 2007 and September 2010. The aim of the study was to determine whether periodic risk assessment and subsequent care planning with people receiving forensic psychiatric out-patient care were associated with a reduction of recidivism and improvement in the person's quality of life, psychosocial functioning and satisfaction with care. If case managers were to have clients randomised to both treatment groups, then this could result in spill-over of the intervention effect. Therefore, we randomised case managers, with their whole case-load, to either care as usual or the intervention. For the clients, a follow-up period of 18 months was planned, or until either end of care or end of study if that were sooner. The primary outcome was the proportion of clients with one or more incidents of violent or criminal behaviour in the 6 months before end of follow-up. Case managers recorded incidents of violent or criminal behaviour on a standard form in the case file (see online data supplement DS1 for a more detailed description of the method).

\section{Participants}

Based on a pilot study, ${ }^{10}$ a power analysis indicated that 340 participants should be included in each study group (see online 
data supplement). Our study was conducted in three out-patient forensic psychiatric services in each of the three northern provinces of The Netherlands, whose case-loads were representative of the country as a whole. ${ }^{12}$ All case managers and clients of the participating services were eligible for the study. We defined case managers as those with primary responsibility for the care planning of their clients. As we expected the intervention to be effective only in longer-lasting treatment relations, ${ }^{11}$ we excluded cases with expected discharge within 6 months or with infrequent treatment contacts (less than once a month on average). Informed consent was asked for client interviews at baseline and follow-up. Approval was obtained from the Dutch medical ethical committee for mental healthcare.

\section{Randomisation}

After initial interviews (by N.A.C.T.) with the case managers to determine their eligibility and characteristics, the second author (R.H.S.v.d.B.), who was masked to the case managers' identities, executed the randomisation procedure. Case managers were randomised consecutively, in random order, in strata defined by participating service, composition of case-load (predominantly clients with violent $v$. sexual offences), professional background (academic $v$. non-academic) and years of experience in forensic psychiatry (2 or more years $v$. less). Further details of the randomisation procedure are given in the online data supplement.

\section{Intervention}

In the control group, case managers provided care as usual to their clients; this did not involve standardised methods of risk assessment or care plan evaluation other than on an incidental and ad hoc basis. Case managers in the intervention group provided regular care and were instructed to use the RACE protocol for all evaluations of their clients' treatment plans. Legally, treatment plan evaluation should occur at least once a year. Since the intervention adopted a noticeably different approach to the treatment plan evaluations compared with procedures in care as usual, masking of clients or case managers was not an option.

Care as usual consisted of combinations of medication, individual (psycho)therapy, forensic psychiatric home care, specialised groups and training modules. Examples of specialised groups are those for hands-on sex offenders, hands-off sex offenders, and those with impulse control disorders, autism spectrum disorders or borderline intellectual functioning. Training modules for social, vocational, living and communication skills as well as those addressing insight were available.

The intervention consisted of two parts: a structured approach to risk assessment, and a care plan evaluation utilising the key strengths and vulnerabilities identified during the first part of the intervention. According to our protocol, case managers first assessed the client's risk and protective factors with the START. Independently, clients did the same using a specially developed client version of the START (available from the authors). Both case manager and client identified the client's key strengths and critical vulnerabilities and then discussed them with each other in a structured way, with the aim of agreeing on the types of care to be included in the new treatment plan. To encourage shared decision-making, case managers were instructed to point out the similarities and differences between the key and critical items they selected and those selected by the client, to motivate their own choices and treatment proposals, and to ask clients about their opinions and suggestions for treatment. The emphasis was on reaching an agreement on the final treatment plan that suited both parties. Consecutive treatment plan evaluations should include a review of previous agreements.
Case managers were trained in the use of the Dutch version of the START, ${ }^{13}$ and the structured approach to shared care planning, described earlier. Clients received no training, but case managers answered their questions if necessary. In accordance with the START manual, case managers rated the stable, historical risk factors of their clients (such as early maladjustment, history of violence and prior supervision failure) at baseline, using the Historical, Clinical, Risk Management - 20 (HCR-20). ${ }^{14}$ These historical factors are meant to serve as background information for the interpretation of the variable, dynamic, factors scored on the START. To maintain comparability between the intervention and care as usual groups, case managers rated the factors for all participating clients at baseline.

\section{Outcome}

The primary outcome consisted of the proportion of clients with one or more violent or criminal incidents in the 6 months before the end of follow-up. Both violent and criminal behaviours are considered important indicators of treatment outcome. Violent behaviour included intentional behaviour with the potential to physically harm a person or animal and seriously threatening or intimidating aggression. Criminal behaviour additionally covered such behaviour as exhibitionism, possession of child pornography, stalking, drug dealing, driving without a licence or under influence, possession of an illegal weapon, vandalism and theft. Not included was the use of illegal drugs, since this is not considered a crime under Dutch law. Case managers were instructed to use a standard form to record any incident that could potentially satisfy the definition. The form was included in the client's case file. Definition of an incident as violent or criminal was determined through consensus among three forensic psychiatric experts, unaware of the randomisation status of the client.

Additional outcome information was collected during interviews at baseline and follow-up with clients who were willing to participate and provided consent. Trained research assistants used an extended version of the MacArthur Violence Screens when asking about incidents in the previous 6 months. ${ }^{15}$ Incidents reported by clients during these interviews were coded and analysed in the same way as incidents reported in case files. Interviewers were masked to client randomisation status.

\section{Statistical analysis}

Incident reports obtained from either case files or client interviews were analysed separately. Outcome was coded as either presence (1) or absence (0) of violent or criminal incidents during the 6 months prior to follow-up. Baseline incidents were coded in a similar manner for the 6 months prior to the baseline assessment. Differences in baseline and follow-up proportions of the outcome were calculated with a chi-squared test for paired observations (McNemar's test). The intervention effect was tested in a logistic multilevel analysis, ${ }^{16}$ based on intention to treat, controlling for violent or criminal behaviour at baseline and length of follow-up. Clients were the first-level units of analysis; case managers were considered a random factor and formed the second-level units. Analyses were conducted with MLwiN version $2.23^{17}$ and PASW Statistics version 18.0.3 on Windows 7.

\section{Results}

We randomised 58 case managers, of whom 24 (41\%) were men, with an average age of 41.7 years (s.d. $=10.4$, range $22-59$ ) at the start of the study. The majority $(n=37,64 \%)$ had not obtained an 
academic degree but $35(60 \%)$ had at least 2 years' experience in forensic psychiatry (mean 7.4 years, s.d. $=5.8$, range $0-20$ ); their individual case-loads consisted, on average, of 17 clients (s.d. $=10$, range $1-40)$. Most case managers $(79 \%, n=46)$ provided treatment in an individual rather than a group setting, and their main focus was on clients with aggressive or other problems (59\%, $n=34)$, although some of them focused solely on sex offenders $(17 \%, n=10)$ or provided only forensic psychiatric home care $(24 \%, n=14)$. Nineteen case managers left their post during the study; where possible, their clients were transferred to another case manager in the same study group, otherwise they were excluded ( $n=3)$ (Fig. 1).

To include clients in the study, case managers conducted a baseline rating of their client's functioning. For 43.7\% $(n=492)$ of the 1127 eligible clients this initial rating could not be completed in time, i.e. before end of care or end of the study inclusion period, and therefore these clients had to be excluded along with 3 clients $(0.3 \%)$ whose case manager had left. There were some minor, clinically irrelevant, differences between included and excluded clients (see online supplement). Characteristics of the clients included in the intervention and control groups are presented in Table 1. Clients in the two groups were of similar age (mean 39.6 years, s.d. $=11.9$, range $18-82$ ). Those in the

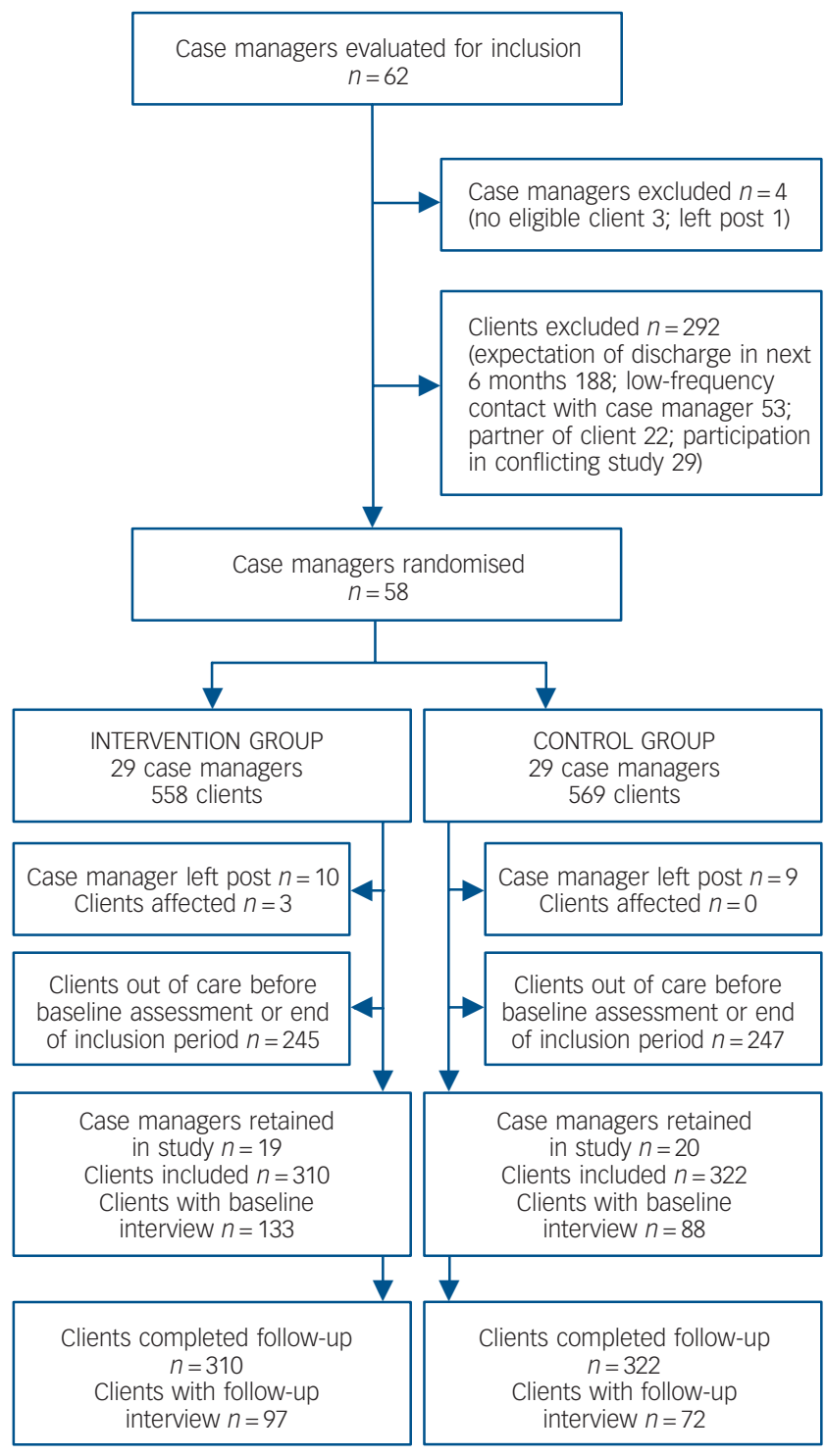

Fig. 1 Study profile. intervention group were more likely to be men $(94.2 \% v$. $87.0 \%)$ and more often had a history of property offences $(36.7 \%$ v. $28.4 \%)$ or substance-related offences ( $15.2 \%$ v. $8.7 \%)$ compared with the control group. There was no difference in diagnostic characteristics, legal order or mean score on the historical risk factors of the HCR-20.

Overall, a third $(35.0 \%, n=221)$ of included clients agreed to an interview with a research assistant at baseline, of whom threequarters $(76.5 \%, n=169)$ also completed an interview at follow-up. More clients in the intervention group agreed to a baseline interview than in the control group (42.9\% v. $27.3 \%$, $P<0.01$ ), but there was no significant difference in the proportion of clients failing to attend the follow-up interview (27.1\% v. $18.2 \%, P=0.13$ ).

\section{Fidelity to study plan}

The follow-up period was 16.2 months on average (s.d.=5.3, range 6-38). The control and intervention groups did not differ in this respect: mean $16.0 \quad$ (s.d.=4.8) v. 16.4 (s.d.=5.8); $P=0.37$. Of the 310 clients in the intervention group, 201 $(64.8 \%)$ received the intervention, i.e. had a care plan evaluation according to the RACE protocol, of whom $72(23.2 \%)$ received the intervention, as planned, more than once (range 2-4; total number of interventions 297). Case managers completed 326 START assessments for 203 clients (range 1-6 per client), and 199 clients completed 293 client versions of the START (range 1-4).

The 109 clients in the intervention group who did not receive an intervention (35.2\%) had been in care longer before their inclusion in the study than those who received several interventions (30.2 months v. 19.5 months, $P=0.02$ ). Participants receiving more than one intervention were more likely than those with no or only one intervention to have committed a sexual offence with a child aged 16 years or under (30.6\% v. 19.7\%, $P=0.05$ ), whereas those who had received at least one intervention were more likely than those receiving none to have committed a sexual offence involving someone over 16 years old or of unknown age $(23.5 \%$ v. $14.5 \%, P=0.06)$. Participants who had received at least one intervention were more likely than clients who had received no intervention to participate in client interviews at baseline $(52.2 \%$ v. $25.7 \%, P<0.01)$ and follow-up (37.8\% v. $19.3 \%, P<0.01$ ). There was no significant difference between the three intervention subgroups in client's gender, age, legal order, psychiatric diagnosis or mean score on the historical risk factors of the HCR-20.

Model fidelity was assessed by observing treatment plan discussions which were scored on a checklist of trained elements of the intervention (see online supplement). On average, $71 \%$ of the trained elements were administered. ${ }^{18}$

\section{Proportion of clients with incidents}

For the two study groups combined a significant reduction from baseline $(21.5 \%)$ to follow-up (15.3\%) was found in the proportion of clients with an incident reported by the case manager in the case file (reduction $6.2 \%, 95 \%$ CI 2.3-10.1, $n=632$; McNemar's $\left.\chi^{2}(1)=8.75, \quad P<0.01\right)$. Case manager-reported frequencies of violent and criminal behaviour are shown in Table 2. Because of the small numbers involved, testing for differences between individual types of incident was considered inappropriate. Although proportions of client-reported incidents were higher than case manager-reported incidents at both baseline (52.1\%) and follow-up (40.8\%), analyses showed similar results. For reason of conciseness we only describe the results for case manager-reported outcomes here; client-reported outcomes are given in online Table DS1. 
Table 1 Characteristics of the included participants $(n=632)$

\begin{tabular}{|c|c|c|c|}
\hline & $\begin{array}{l}\text { Intervention group } \\
\qquad(n=310)\end{array}$ & $\begin{array}{l}\text { Control group } \\
\qquad(n=322)\end{array}$ & $P$ \\
\hline Age, years: mean (s.d.) & $40.0(11.2)$ & $39.1(12.4)$ & 0.37 \\
\hline Gender, \% male & 94.2 & 87.0 & $<0.01$ \\
\hline Duration of care before inclusion, months: mean (s.d.) & $25.6(24.3)$ & $26.7(25.4)$ & 0.59 \\
\hline Attended baseline interview, \% & 42.9 & 27.3 & $<0.01$ \\
\hline Attended follow-up interview, \% & 31.3 & 22.4 & 0.01 \\
\hline HCR-20 score, historical items: mean (s.d.) & $7.8(3.7)$ & $8.0(3.9)$ & 0.51 \\
\hline $\begin{array}{l}\text { Legal order at start of treatment, } \%^{\mathrm{a}} \\
\text { Criminal treatment order } \\
\text { Civil treatment order } \\
\text { Probation } \\
\text { No order/voluntary }\end{array}$ & $\begin{array}{c}16.2 \\
0.6 \\
27.8 \\
55.3\end{array}$ & $\begin{array}{c}16.6 \\
1.3 \\
27.6 \\
54.5\end{array}$ & 0.89 \\
\hline $\begin{array}{l}\text { Forensic history, } \% \\
\text { Sexual offence against person } \leqslant 16 \text { years old } \\
\text { Sexual offence against person }>16 \text { years old or unspecified } \\
\text { Violent offence } \\
\text { Arson } \\
\text { Stalking } \\
\text { Property offence } \\
\text { Substance-related offence }\end{array}$ & $\begin{array}{l}20.4 \\
22.3 \\
55.7 \\
6.1 \\
3.2 \\
36.7 \\
15.2\end{array}$ & $\begin{array}{c}20.8 \\
17.7 \\
52.2 \\
5.0 \\
4.3 \\
28.4 \\
8.7\end{array}$ & $\begin{array}{l}0.90 \\
0.15 \\
0.38 \\
0.52 \\
0.47 \\
0.03 \\
0.01\end{array}$ \\
\hline $\begin{array}{l}\text { Psychiatric diagnosis, \% } \\
\text { Axis I disorder }\end{array}$ & & & \\
\hline $\begin{array}{l}\text { Psychotic disorder } \\
\text { Impulse control disorder } \\
\text { Paraphilia } \\
\text { Substance-related disorder } \\
\text { Mood disorder } \\
\text { Other Axis I disorder } \\
\text { No Axis I disorder }\end{array}$ & $\begin{array}{c}7.2 \\
26.6 \\
20.4 \\
37.8 \\
21.1 \\
37.3 \\
6.9\end{array}$ & $\begin{array}{c}6.6 \\
26.3 \\
19.7 \\
31.7 \\
16.9 \\
39.4 \\
8.5\end{array}$ & $\begin{array}{l}0.75 \\
0.93 \\
0.84 \\
0.11 \\
0.19 \\
0.58 \\
0.46\end{array}$ \\
\hline $\begin{array}{l}\text { Axis II disorder } \\
\text { Cluster A personality disorder } \\
\text { Cluster B personality disorder } \\
\text { Antisocial personality disorder } \\
\text { Borderline personality disorder } \\
\text { Cluster C personality disorder } \\
\text { Personality disorder NOS } \\
\text { No personality disorder or missing diagnosis } \\
\text { Borderline intellectual functioning or less }\end{array}$ & $\begin{array}{l}1.3 \\
26.3 \\
10.5 \\
15.5 \\
11.2 \\
32.6 \\
31.2 \\
11.5\end{array}$ & $\begin{array}{c}1.3 \\
27.3 \\
10.7 \\
12.5 \\
9.4 \\
29.8 \\
34.2 \\
11.0\end{array}$ & $\begin{array}{l}0.95 \\
0.79 \\
0.96 \\
0.29 \\
0.47 \\
0.45 \\
0.44 \\
0.83\end{array}$ \\
\hline
\end{tabular}

\section{Intervention effect}

Logistic multilevel analyses were performed for incidents at follow-up obtained from case files (Table 3 ) and from client interviews (online Table DS2). Both analyses were based on intention to treat, and included all participants in the intervention group regardless of the number of interventions they had received. Using case-file data there was no significant effect for clients in the intervention group to be either more or less likely (odds ratio $(\mathrm{OR})=1.46$, 95\% CI 0.89-2.44, $P=0.15$ ) to have had an incident at follow-up than control group participants. Findings regarding the implementation of the intervention warranted additional logistic multilevel analyses for 'as treated' comparisons (including only clients who received at least one intervention) and 'as planned' comparisons (including only clients with more than one intervention) with the control group. Results of these analyses did not change intention-to-treat findings ('as treated' $\mathrm{OR}=1.34,95 \% \mathrm{CI} 0.76-2.38, P=0.32$; 'as planned' $\mathrm{OR}=1.89,95 \%$ CI $0.89-3.99, P=0.10)$.

\section{Discussion}

The preventive effect of risk assessment in general - and for forensic psychiatry in particular - as mediated by better or more suitable treatment for clients has not been studied adequately. We examined whether risk assessment and subsequent shared care planning, in which the case manager and client together translate the identified risks and needs into a treatment plan, reduced violent and criminal behaviour by people using out-patient forensic psychiatric services. During treatment there was an overall reduction in the proportion of clients with recidivism. However, no additional reduction was achieved by the intervention. We therefore have to conclude that our study does not show that risk assessment combined with shared decision-making in subsequent care planning results in a preventive effect on violent or criminal behaviour of this client group.

How to interpret these results? Is risk assessment with shared care planning ineffective in reducing violent and criminal behaviour? Or are firm conclusions precluded because the implementation of the study was wanting? Arguments for both interpretations are discussed. First, we lost almost half (44\%) of our eligible clients because case managers did not assess client baseline functioning in time to include these cases in the study. The delay in baseline assessment also caused the included participants to be in treatment longer before they received the intervention. On average these individuals were in care for 26 months before inclusion, so those in the intervention group had 


\begin{tabular}{|c|c|c|c|c|c|c|}
\hline & \multicolumn{3}{|c|}{ Baseline, $n(\%)$} & \multicolumn{3}{|c|}{ Follow-up, $n$ (\%) } \\
\hline & $\begin{array}{l}\text { Whole sample } \\
\qquad(n=632)\end{array}$ & $\begin{array}{l}\text { Intervention group } \\
\qquad(n=310)\end{array}$ & $\begin{array}{l}\text { Control group } \\
\qquad(n=322)\end{array}$ & $\begin{array}{l}\text { Whole sample } \\
\qquad(n=632)\end{array}$ & $\begin{array}{l}\text { Intervention group } \\
\qquad(n=310)\end{array}$ & $\begin{array}{l}\text { Control group } \\
\qquad(n=322)\end{array}$ \\
\hline \multicolumn{7}{|l|}{ Sexual offence } \\
\hline Against person $\leqslant 16$ years old & $6(0.9)$ & $3(1.0)$ & $3(0.9)$ & $5(0.8)$ & $4(1.3)$ & $1(0.3)$ \\
\hline Against person $>16$ years old or unspecified & $6(0.9)$ & $4(1.3)$ & $2(0.6)$ & $5(0.8)$ & $4(1.3)$ & $1(0.3)$ \\
\hline Violence & $53(8.4)$ & $26(8.4)$ & $27(8.4)$ & $41(6.5)$ & $20(6.5)$ & $21(6.5)$ \\
\hline Threatening aggression ${ }^{a}$ & $63(10.0)$ & $30(9.7)$ & $33(10.2)$ & $39(6.2)$ & $27(8.7)$ & $12(3.7)$ \\
\hline Arson & $2(0.3)$ & $1(0.3)$ & $1(0.3)$ & $1(0.2)$ & $0(0.0)$ & $1(0.3)$ \\
\hline Stalking & $4(0.6)$ & $1(0.3)$ & $3(0.9)$ & $1(0.2)$ & $1(0.3)$ & $0(0.0)$ \\
\hline Property offence & $27(4.3)$ & $9(2.9)$ & $18(5.6)$ & $18(2.8)$ & $7(2.3)$ & $11(3.4)$ \\
\hline Substance-related offence ${ }^{b}$ & $12(1.9)$ & $4(1.3)$ & $8(2.5)$ & $6(0.9)$ & $3(1.0)$ & $3(0.9)$ \\
\hline Any violent or criminal $\mathrm{act}^{\mathrm{C}}$ & $136(21.5)$ & $66(21.3)$ & $70(21.7)$ & 97 (15.3) & $56(18.1)$ & $41(12.7)$ \\
\hline \multicolumn{7}{|c|}{$\begin{array}{l}\text { a. Includes threatening verbal and non-verbal aggression. } \\
\text { b. Includes sale or production of illegal substances and driving while under the influence of a substance. Does not include use or misuse of illegal substances. } \\
\text { c. Numbers do not add up owing to fitting multiple categories and multiple incidents during observation periods. Low numbers prevented testing for differences on individual } \\
\text { types of incident. }\end{array}$} \\
\hline
\end{tabular}

already developed a way of interacting and care planning with their case manager before they were introduced to our intervention. In these circumstances the effect of the intervention on violent and criminal behaviour might have been less than when the intervention was used to shape the therapeutic relationship from the start. Furthermore, treatment during the delay period might have already reduced the incidence of violent and criminal behaviour, making it harder to realise and show an additional intervention effect.

Imperfect implementation of our study plan is also plain in the number of clients in the intervention group who did not receive the intervention (35\%), or received it only once $(42 \%)$ rather than several times as planned. If the intervention is not delivered, one should not expect an effect, or - as in the second subgroup - one should not expect the intended effect size. The introduction of shared decision-making in treatment relations has been shown to increase patient satisfaction, treatment adherence and quality of life, but only in longer-lasting treatment relations and when it is part of a process of care rather than an isolated event. ${ }^{11,19}$ Repeating the intervention, therefore, seems imperative to achieve an effect on client behaviour. However, additional 'as treated' and 'as planned' analyses did not show an intervention effect either. The results of such analyses should be interpreted with caution, since participants who received the intervention one or more times might be selected groups. Nevertheless, the negative results of these additional analyses make it unlikely that imperfect implementation could be the sole explanation for not finding an effect of the intervention on violent and criminal behaviour.

Possibly the intervention was ineffective in the setting in which it was studied, for example because usual care is already good at reducing recidivism. The overall reduction in proportions of clients with incidents from baseline to follow-up seems to confirm this. However, this may not be interpreted as an effect of treatment

Table 3 Intervention effect on violent or criminal incidents

\begin{tabular}{|lcr|}
\hline \multirow{2}{*}{ Incidents at baseline (yes) } & \multicolumn{2}{c|}{ Case-file data $(n=632)$} \\
\cline { 2 - 3 } & OR $(95 \% \mathrm{Cl})$ & \multicolumn{1}{c|}{$P$} \\
\hline Duration of follow-up & $2.14(1.32-3.47)$ & $<0.01$ \\
\hline Intervention & $0.98(0.94-1.02)$ & 0.35 \\
\hline
\end{tabular}

per se, as it might also be the result of independent processes such as spontaneous recovery or intensification of supervision. As noted earlier, the long period of usual care before client inclusion could have limited the effectiveness of the intervention once clients were exposed to it. Also, the possibility remains that the intervention might not have been much of an improvement over good-quality usual care provided by the rather experienced case managers participating in this study. Additionally, it could be that the intervention was ineffective because case managers might have been unable to make the necessary translation of the identified risks and needs into effective treatment. Douglas \& Kropp refer to this as an 'ongoing risk reassessment and management revision process' to achieve what they call a 'prevention-based paradigm for violence risk assessment. ${ }^{6}$ Possibly case managers were unable to identify or implement effective treatment appropriate to the identified risks and needs. For example, it may be difficult to do anything about a client's poor financial situation or to change an ongoing destructive relationship. The case managers may simply have been unable to do anything about the risks and needs they saw.

Finally, the intervention may not have had a preventive effect on violent and criminal behaviour because shared care planning shifted the focus of treatment from the 'criminogenic' needs of the client, i.e. those that are predictive of antisocial behaviour, to quality-of-life needs that are unrelated to such behaviour. This is the principal objection by supporters of the Risk-NeedResponsivity model of offender rehabilitation to the competing Good Lives model. ${ }^{20}$ The latter model argues that criminal behaviour is an inappropriate way of fulfilling basic human needs, and that it may be counteracted by developing socially acceptable ways to fulfil those needs. ${ }^{2}$ Those favouring the Risk-NeedResponsivity model contest this, claiming that successful enhancement of the well-being of offenders may even increase crime if major criminogenic risks are not addressed. ${ }^{20}$ It is pointed out, for example, that traditional clinical treatment targets such as anxiety and emotional empathy fail to demonstrate predictive validity for criminal behaviour. ${ }^{1}$ This would mean that only case manager- selected, empirically supported 'criminogenic' treatment goals could reduce recidivism among forensic psychiatric clients, and that the shared decision-making we introduced in treatment planning might in fact be undesirable in this setting.

Although we found no effect of our intervention on violent and criminal behaviour in this sample, the intervention might well have altered the therapeutic relationship between client and case 
manager. Reactions of case managers indicated that they valued aspects of the intervention and that they wanted to maintain elements such as the structured risk assessment by both case manager and client. In addition, the shared decision-making in care planning may have increased patient satisfaction and quality of life, as reported for this approach in general. ${ }^{11}$

\section{Study strengths and limitations}

To our knowledge this is the first investigation of the preventive effect of risk assessment in clinical practice. Studies so far have reported only on prediction with the aid of risk assessment, even though the ultimate goal of forensic psychiatric treatment is prevention. ${ }^{6}$ Also, we included clients' self-assessment of their vulnerabilities and strengths on the START and implemented a care planning procedure explicitly based on principles of shared decision-making. We consider both elements useful to encourage clients to be more involved with their treatment - an issue that is of particular importance in forensic psychiatry, where people often enter treatment under formal or informal coercion. In out-patient forensic psychiatry case managers are additionally confronted frequently with people they consider to be in need of continued care, even after the treatment order has expired. Therefore, motivating the individual to seek treatment is of crucial importance in this setting. Shared decision-making may be useful for reaching this goal, ${ }^{11}$ although we could not find positive effects for it on client violent or criminal behaviour. Our study shows that taking the client's perspective into account may be worthwhile in forensic psychiatry. Many more participants reported a violent or criminal incident in the study interviews than were registered by their case managers in their case files. Systematically enquiring about the clients' ideas about risks, strengths and needs may stimulate disclosure and encourage clients to become more involved in their treatment. Both clients and case managers considered the client self-appraisal version of the START an interesting option to attain this goal.

Our study has several limitations, such as the delay in study inclusion and the proportion of clients in the intervention group not receiving the intervention, or receiving it only once. Additionally, a limited number of participants agreed to be interviewed at baseline and follow-up (35\% and 27\% respectively), and this was significantly lower in the control group than in the intervention group. Apart from mere chance, this difference might also indicate that case managers in the control group felt less involved in the study than their colleagues in the intervention group. The former had fewer contacts with research staff and fewer tasks related to the study than the latter. This may explain why they possibly were less committed to the study. Limited success in motivating the case managers to carry out activities for the study, therefore, appears to be an overarching theme in all the above limitations of the study. Case managers experienced the study tasks as burdensome and difficult to combine with their clinical work. Many of these tasks were necessary for the study but not part of the intervention itself. Therefore, they further complicated the already difficult undertaking of implementing a new intervention in practice, and testing its effect in a pragmatic clinical trial. Finally, our data and study design prevented us from examining the independent effects the use of risk assessment instruments and the shared decision-making approach had on the outcome, and whether the intervention led to adjustments in treatment, in response to identified needs and risks, and hence to differences in treatment between the study groups.

\section{Implications of the study}

Although risk assessment is a common practice in forensic psychiatric care, it remains unclear whether it actually helps to achieve the ultimate treatment goal of prevention of violent or criminal behaviour. Our study indicates that this goal may not be reached through risk assessment embedded in shared decision-making.

\footnotetext{
Nadine A. C. Troquete, MSC, Rob H. S. van den Brink, PhD, Rob Giel Research Center, University Medical Center Groningen; Harry Beintema, MD, Mental Health Organisation Lentis and Forensic Psychiatric Clinic dr S. van Mesdag, Groningen; Tamara Mulder, MD, Mental Health Organisations Drenthe, Assen; Titus W. D. P. van Os, MD, PhD, Mental Health Organisations Friesland, Leeuwarden; Robert A. Schoevers, MD, PhD, Durk Wiersma, PhD, Rob Giel Research Center, University Medical Center Groningen, The Netherlands

Correspondence: Nadine Troquete, Rob Giel Research Center, University Centre for Psychiatry, University Medical Centre Groningen, CC72, PO Box 30.001 9700 RB Groningen, The Netherlands. Email: N.A.C.Troquete@umcg.nl

First received 10 Apr 2012, final revision 19 Dec 2012, accepted 8 Jan 2013
}

\section{Funding}

The study was funded by a grant from ZonMw, The Netherlands Organisation for Health Research and Development (grant 100003023). Further funding was provided by the participating mental health organisations of Drenthe, Friesland and Groningen (Lentis) and the University Centre of Psychiatry of the University Medical Centre, Groningen.

\section{Acknowledgements}

We express our great appreciation to all case managers, other staff and clients of the mental health organisations of Drenthe, Friesland and Lentis, who contributed to this study.

\section{References}

1 Andrews DA, Bonta J. The Psychology of Criminal Conduct (2nd edn). Anderson, 2010

2 Ward T, Mann RE, Gannon TA. The good lives model of offender rehabilitation: clinical implications. Aggress Violent Behav 2007; 12: 87-107.

3 Webster CD, Nicholls TL, Martin M-L, Desmarais SL, Brink J. Short-Term Assessment of Risk and Treatability (START): the case for a new structured professional judgment scheme. Behav Sci Law 2006; 24: 747-66.

4 Nicholls TL, Brink J, Desmarais S, Webster CD, Martin M. The Short-Term Assessment of Risk and Treatability (START): a prospective validation study in a forensic psychiatric sample. Assessment 2006; 13: 313-27.

5 De Vogel V, de Ruiter C, Bouman Y, de Vries Robbé M. SAPROF. Guidelines for the Assessment of Protective Factors for Violence Risk (English Version). Forum Educatief, 2009

6 Douglas KS, Kropp PR. A prevention-based paradigm for violence risk assessment: clinical and research applications. Crim Justice Behav 2002; 29 617-58.

7 Drieschner $\mathrm{KH}$, Boomsma A. The Treatment Motivation Scales for Forensic Outpatient Treatment (TMS-F). Assessment 2008; 15: 224-41.

8 Dvoskin J, Heilbrun K. Risk assessment and release decision-making: toward resolving the great debate. J Am Acad Psychiatry Law 2001; 29: 6-10.

9 Douglas KS, Skeem JL. Violence risk assessment - getting specific about being dynamic. Psychol Public Policy Law 2005; 11: 347-83.

10 Van den Brink RHS, Hooijschuur A, van Os TWDP, Savenije W, Wiersma D. Routine violence risk assessment in community forensic mental healthcare. Behav Sci Law 2010; 28: 396-410.

11 Joosten EAG, DeFuentes-Merillas L, de Weert GH, Sensky T, van der Staak CPF, de Jong CAJ. Systematic review of the effects of shared decisionmaking on patient satisfaction, treatment adherence and health status. Psychother Psychosom 2008; 77: 219-26.

12 Bouman YHA, de Ruiter C, Schene AH. Social ties and short-term selfreported delinquent behaviour of personality disordered forensic outpatients. Legal Criminol Psychol 2010; 15: 357-72.

13 't Lam K, Lancel M, Hildebrand M. Manual for the Short-Term Assessment of Risk and Treatability (START): Guidelines for Assessment of Short-Term Risks and Treatment Opportunities (Dutch translation). GGZ Drenthe, 2009.

14 Webster CD, Douglas KS, Eaves D, Hart S. HCR-20: Assessing the Risk of Violence. Version 2. Simon Fraser University/Forensic Psychiatric Service Commission of British Columbia, 1997.

15 Monahan J, Steadman $\mathrm{H}$, Silver E, Appelbaum $\mathrm{P}$, Robbins $\mathrm{P}$, Mulvey E, et al. Rethinking Risk Assessment: The MacArthur Study of Mental Disorder and Violence. Oxford University Press, 2001. 
16 Snijders TAB, Bosker RJ. Multilevel Analysis. An Introduction to Basic and Advanced Multilevel Modeling. Sage, 1999.

17 Rasbash J, Browne W, Healy M, Cameron B, Charlton C. MLwiN Version 2.23. Centre for Multilevel Modelling, University of Bristol, 2011.

18 De Bruijn CWA. Model fidelity and shared decision making in the intervention of the Risk Assessment and Care Evaluation Study. Thesis, University Centre for Psychiatry, Faculty of Medical Sciences, University of Groningen, 2010.
19 Priebe S, McCabe R, Bullenkamp J, Hansson L, Lauber C, Martinez-Leal R, et al. Structured patient-clinician communication and 1-year outcome in community mental healthcare. Cluster randomised controlled trial. Br J Psychiatry 2007; 191: 420-6.

20 Andrews DA, Bonta J, Wormith JS. The Risk-Need-Responsivity (RNR) model: does adding the Good Lives Model contribute to effective crime prevention? Crim Justice Behav 2011; 38: 735-55.

\section{reflections On Bowlby's 'trilogy'}

\section{Jeremy Holmes}

Bowlby's 'trilogy' - Attachment, Separation, and Loss - had, by 2010, been cited over 12000 times. By this measure at least, John Bowlby is the most influential psychoanalyst of all time, establishing a new developmental paradigm. Yet Bowlby's initial aims were relatively modest. He wanted to observe and understand the responses of children separated from their mothers and their developmental sequelae. Attachment lays out, in typical Bowlbian fashion, a logical, exhaustive account demolishing existing theories of the parent-infant bond - psychoanalytic and behavioural - clearing the way for his own novel model. Drawing on neo-Darwinistic ethology and control systems theory, he proposed attachment as a primary motivational force. The attachment dynamic is a product of our 'environment of evolutionary adaptation' in which protection from predation was essential. The 'set goal' of attachment is physical proximity to a secure base when a child is threatened, stressed, or ill. Only once attachment needs are assuaged, can exploration and play resume.

Attachment theory's co-creator was Mary Ainsworth. Separation is largely devoted to the implications of the 'strange situation', which she devised, in which individual differences in 1-year-olds' responses to brief separations from parents are reliably observed and classified. The familiar concepts of secure and insecure attachment and its subtypes, insecure-avoidant, insecure-ambivalent and insecure-disorganised, flow from this work. Ainsworth established that maternal sensitivity and responsiveness in the first year of life was the key to later security. Longitudinal studies have shown how social competence is linked to early security of attachment, supporting the psychoanalytic hypothesis of the determining influence of early relationships.

In Separation Bowlby analysed anxiety disorders, especially agoraphobia, in terms of insecure attachment. He saw anger as a normal and adaptive response to separation, a negative reinforcement schedule aimed at maintaining proximity. The clinical manifestations of anger, including self-harm, and the rage of people with borderline personality disorder, can be seen as pathological attempts to restore a modicum of security in the face of overwhelming threat. Loss was strongly influenced by two attachment-influenced sets of research paradigms: Parkes' studies of bereavement, and Brown and Harris's studies of loss and depression. The presence of a secure base and the quality of attachment crucially determine whether depression or recovery is the outcome of loss or death.

Bowlby's trilogy remains the secure foundation for half a century of 'normal science' (the post-paradigm phase). Mary Main identified disorganised attachment as a risk factor for severe psychopathology, devising the Adult Attachment Interview as a systematic measure of mental representations of attachment. Fonagy and colleagues have extended her model into the concept of 'mentalising' and its deficiency in psychopathology.

Some paradigm shifts feel so familiar that one thinks 'why had no one thought of that before?' The trilogy stirred up much opposition, but attachment is now part of the air we breathe. Bowlby bemoaned the divide between 'biological' and psychodynamic psychiatry, insisting that his ethological-developmental model was rooted in evolutionary biology. Today's epigenetics and neuropsychoanalysis suggest that divide is narrowing. Psychiatry is on the brink of another paradigm shift; one that Bowlby would have welcomed. 